\title{
Metronome-Paced Incremental Hyperventilation May Predict Exercise Tolerance and Dyspnea as a Surrogate for Dynamic Lung Hyperinflation During Exercise
}

This article was published in the following Dove Press journal:

International Journal of Chronic Obstructive Pulmonary Disease

\author{
Shohei Kawachi (iD) \\ Keisaku Fujimoto $\mathbb{D}^{2}$ \\ 'Department of Biomedical Laboratory \\ Science, Graduate School of Medicine, \\ Shinshu University, Nagano 390-862I, \\ Japan; ${ }^{2}$ Department of Clinical \\ Laboratory Sciences, Shinshu University \\ School of Health Sciences, Nagano 390- \\ 8621, Japan
}

Background: Dynamic lung hyperinflation (DLH) has been evaluated based on decreased inspiratory capacity (IC) during exercise load. However, this is not routinely done in clinical practice. We have developed a convenient method of metronome-paced incremental hyperventilation (MPIH) and reported its usefulness. In the present study, we compared these two methods for evaluating DLH and examined whether our MPIH method can be used to predict DLH during exercise.

Methods: DLH was measured by MPIH and constant load exercise (CLE) in 35 patients with stable COPD. DLH was defined as the most decreased IC ( $\left.\mathrm{IC}_{\text {lowest }}\right)$ and the most decreases in IC from IC at rest ( $\left.-\mathrm{IC}_{\text {lowest }}\right)$, and we compared between these two methods.

Results: The $\mathrm{IC}_{\text {lowest }}$ in $\mathrm{CLE}$ and the $-\mathrm{IC}_{\text {lowest }}$ in $\mathrm{MPIH}$ were significantly lower in emphysemadominant COPD than in emphysema-nondominant COPD. Both $\mathrm{IC}_{\text {lowest }}$ and $-\mathrm{IC}_{\text {lowest }}$ showed significant correlations between the two methods $(\mathrm{r}=0.67, p<0.01$ and $\mathrm{r}=0.44, p<0.01$, respectively). The endurance time of CLE was significantly correlated with $\mathrm{IC}_{\text {lowest }}$ following MPIH $(\mathrm{r}=0.62, p<0.01)$ but not with that obtained by the CLE method. Furthermore, the $\mathrm{IC}_{\text {lowest }}$ of MPIH was more significantly correlated with endurance time in emphysema-dominant COPD. Weak but significant correlations between the $-\mathrm{IC}_{\text {lowest }}$ obtained by each method and maximum modified Borg scale were observed (MPIH: $\mathrm{r}=0.38, p=0.02$; CLE: $\mathrm{r}=0.37, p=0.03$ ).

Conclusion: The MPIH method may be a convenient method to predict exercise tolerance and dyspnea as a clinically useful synergic screening surrogate for DLH during exercise.

Keywords: dynamic lung hyperinflation, constant load exercise, hyperventilation, endurance time, inspiratory capacity

\section{Introduction}

Dynamic lung hyperinflation (DLH) is an important factor involved in dyspnea on exertion and exercise intolerance in chronic obstructive pulmonary disease (COPD), and should be assessed in patients. ${ }^{1,2}$ In COPD, both the decrease in lung elastic recoil pressure and narrowing of the peripheral bronchial lumen induce irreversible airflow obstruction, which results in lung hyperinflation. ${ }^{2}$ On exertion, the hyperinflation progresses due to air trapping dependent on the increase in respiratory rate, which is called DLH. $^{3}$

DLH is generally evaluated as the decreased inspiratory capacity (IC) during exercise load test. ${ }^{4,5}$ The IC is measured at regular intervals during constant load 
exercise (CLE), and the decreased IC during exercise is used as an index of DLH. ${ }^{1}$ However, the measurement of IC during exercise load test is complicated, requires special instruments, and is difficult to perform routinely at clinical sites. Therefore, we developed a convenient method of metronome-paced incremental hyperventilation (MPIH) for assessment of DLH without exercise load, and have reported its usefulness for evaluating the efficacy of bronchodilators. ${ }^{6,7}$ Furthermore, we developed a dedicated spirometer for the measurement of DLH by MPIH and reported its usefulness. ${ }^{7,8}$ The spirometer was released 1 year ago in Japan and has been used for DLH measurement at clinical sites. However, the correspondence between the conventional method of CLE and our developed MPIH method has not been elucidated. In the present study, we examined whether the decreases in IC following MPIH correspond to the DLH assessed by the CLE method and can be used to predict exercise tolerance and dyspnea as a surrogate for DLH during exercise in COPD.

\section{Materials and Methods}

\section{Subjects}

The study population consisted of patients with stable COPD who visited Shinshu University Hospital (Matsumoto, Nagano, Japan) between June 8, 2017, and September 30, 2019. COPD was diagnosed according to the Global Initiative for Chronic Obstructive Lung Disease (GOLD) criteria. ${ }^{9}$

Patients with exacerbation and/or respiratory infection within 3 months, prior history of lung surgery, severe heart disease, or impairment or difficulty in exercise due to motor or cognitive dysfunction were excluded. A history of exacerbation with COPD was defined as acute worsening of respiratory symptoms that resulted in additional therapy. ${ }^{9}$

\section{Study Design}

This study had a prospective cross-sectional design. All subjects were recruited from the outpatient clinic of Shinshu University Hospital and provided informed consent to participate in the present study. First, DLH was measured by the MPIH method following a lung function test and examination of high-resolution computed tomography (HRCT) of the lungs. After the measurements, subjects performed symptom-limited incremental load exercise testing using an ergometer or treadmill. Finally, the subjects underwent DLH measurement during symptom-limited CLE at a load of $60-70 \%$ of the maximum load in the incremental load exercise test. All subjects performed these examinations under their current therapies. All tests were conducted between June 8, 2017, and September 30, 2019. The subjects performed both tests within one day.

The primary outcome was the correlation of the maximum decreased IC ( $\left.\mathrm{IC}_{\text {lowest }}\right)$ or maximum decreases in IC from IC at rest $\left(-\mathrm{IC}_{\text {lowest }}\right)$ as an index of DLH obtained by the MPIH and CLE methods. The secondary outcomes were the correlation between $\mathrm{IC}_{\text {lowest }}$ or $-\mathrm{IC}_{\text {lowest }}$ obtained by the two methods and exercise endurance time or dyspnea on CLE.

\section{Measurement Outcomes}

\section{Lung Function}

Spirometry was performed using a spirometer (Fukuda Denshi Co., Ltd., Tokyo, Japan). Lung volume of functional residual capacity (FRC) and lung diffusion capacity for carbon monoxide (DLCO) were measured using a Chestac-8900 device (Chest Co. Ltd, Tokyo, Japan). FRC was tested using a Body Box, after which the subject immediately inspired to total lung capacity (TLC) and expired maximally to residual volume (RV), allowing the calculation of lung volume and RV/TLC. All measurements were performed according to the Japanese Respiratory Society guidelines for lung function measurements. For predicted values of $\mathrm{FEV}_{1}$ and $\mathrm{VC}$, Japanese local reference data developed by the Japanese Respiratory Society were adopted..$^{10}$ Predicted values for DLCO and lung volumes (RV and TLC) measured by body plethysmography were determined using the respective formulae of Nishida et al and Boren et al. ${ }^{11,12}$

\section{Classification of Phenotypes as Emphysema-Dominant and Emphysema-Nondominant}

The presence of emphysema was evaluated using a helical computed tomography (CT) scanner (LightSpeed, General Electric, Milwaukee, WI) at full inspiration with 1-3 mm collimation $(120 \mathrm{kVp}, 200 \mathrm{~mA}, 1.0$ pitch). The analysis method for the evaluation of emphysema on HRCT images was the same as in our previous study. ${ }^{13}$ Emphysema was scored visually according to the method by Goddard et al. ${ }^{14}$ The score in each field was calculated for the dimensions according to the ratio of low attenuation area, as follows: score 0 , low attenuation area $<5 \%$; score $1,5 \% \leq$ low attenuation area $<25 \%$; score $2,25 \% \leq$ low attenuation area $<50 \%$; score $3,50 \% \leq$ low attenuation area $<75 \%$; and score $4,75 \% \leq$ low attenuation area. The severity of emphysema was graded in accordance with the sum of the scores of the six dimensions, as follows: grade 0 , total 
score $=0 ;$ grade 1, total score $=1-6 ;$ grade 2, total score $=$ 7-12; grade 3, total score $=13-18$; and grade 4, total score $=19-24$. We defined emphysema-dominant COPD as emphysema $\geq$ grade 2 and emphysema-nondominant COPD as emphysema grade $0-1$. CT images were analyzed independently by an experienced pulmonologist (KF).

\section{Measurement of Dynamic Lung Hyperinflation by the Metronome-Paced Incremental Hyperventilation (MPIH) Method}

The measurement of DLH by the method of MPIH using a dedicated spirometer for MPIH (Fukuda Denshi Co., Ltd., Tokyo, Japan) and was performed according to the same method as described in our previous studies. ${ }^{7,8}$ Figure 1 shows the measurement of DLH based on MPIH using a spirometer. First, the resting IC and vital capacity (VC) were measured in usual spirometry mode. Next, the subjects breathed in synchronization with a pulsing sound and light of the spirometer for $30 \mathrm{~s}$ at a respiratory rate of 20 breaths/ min (bpm) followed by maximum inspiratory maneuver, and IC was measured. After a pause of 1-2 minutes, the respiratory rates were increased in steps to $30 \mathrm{bpm}$ for $30 \mathrm{~s}$ and then to $40 \mathrm{bpm}$ for $30 \mathrm{~s}$. At the end of each period of hyperventilation, the subjects performed maximum inspiratory maneuver, and the IC was measured. The measurements of IC following each hyperventilation were repeated three times, and the designated spirometer automatically calculated the average. The IC at rest and the measurements of IC after each hyperventilation at respiratory rates of 20,30, and 40 bpm were expressed as the $\mathrm{IC}_{\text {rest }}, \mathrm{IC}_{20}, \mathrm{IC}_{30}$, and $\mathrm{IC}_{40}$, respectively. The lowest value among $\mathrm{IC}_{20}, \mathrm{IC}_{30}$, and $\mathrm{IC}_{40}$ was adopted as $\mathrm{IC}_{\text {lowest }}$ The decreases in $\mathrm{IC}$ from $\mathrm{IC}_{\text {rest }}$ to $\mathrm{IC}_{\text {lowest }}$ were also evaluated and expressed as $-\mathrm{IC}_{\text {lowest }}$ $\left(\mathrm{IC}_{\text {lowest }}-\mathrm{IC}_{\text {rest }}\right)$.
Incremental Load Exercise Test

Symptom-limited incremental and constant (work) load exercise testing used an ergometer (Corival cpet; Lode B. V. Co., Ltd., Groningen, The Netherlands) or a treadmill (Auto Runner AT-200; Minato Medical Science Co., Ltd., Osaka, Japan), and methods were performed with reference to previous studies. ${ }^{1,15}$ Oxygen uptake $\left(\mathrm{VO}_{2}, \mathrm{~mL} /\right.$ $\mathrm{min})$, carbon dioxide production $\left(\mathrm{VCO}_{2}, \mathrm{~mL} / \mathrm{kg} / \mathrm{min}\right)$, ventilation (VE, L/min), tidal volume (VT, L), and respiratory rate ( $R R$, times/min) were recorded using the breath-bybreath measurements obtained with a breath analyzer system (AE-310S AEROMONITOR; Minato Medical Science Co., Ltd.). These breath-by-breath exercise metabolic indexes were assessed by mean value at peak, which was the average value for $10 \mathrm{~s}$ before the end of exercise. $\mathrm{SpO}_{2}$, pulse rate (PR, beats/min), and electrocardiogram (ECG) were measured continuously with a fingertip monitor (AnypalWalk ATP-W03; Fukuda Denshi Co., Ltd., Tokyo, Japan) and ECG monitor (DS-8007 system; Fukuda Denshi Co., Ltd.) during exercise, and the minimum $\mathrm{SpO}_{2}$ and the maximum PR were recorded.

A treadmill was the first choice for exercise load tests. However, an ergometer was used instead for subjects who had difficulty walking on the treadmill. The incremental load protocol of the treadmill was used "TR-3" which is designed to increase $\dot{\mathrm{VO}}_{2}$ linearly. This ramp load protocol was a method in which the speed and slope changed continuously, as reported previously. ${ }^{16}$ The incremental load of the ergometer used a ramp load with stepwise increments of $10 \mathrm{~W}$ per minute. ${ }^{17}$ Subjects continued to exercise until limited by symptoms and maximum exercise load, defined as the greatest work rate that the subject was able to maintain exercise for $\geq 30 \mathrm{~s}$, was evaluated. Exercise loads during warm-up and cool-down phases consisted of a speed of $1 \mathrm{~km} / \mathrm{h}$ and a slope of $0 \%$ on a treadmill or $10 \mathrm{~W}$ on an ergometer for 3 minutes.

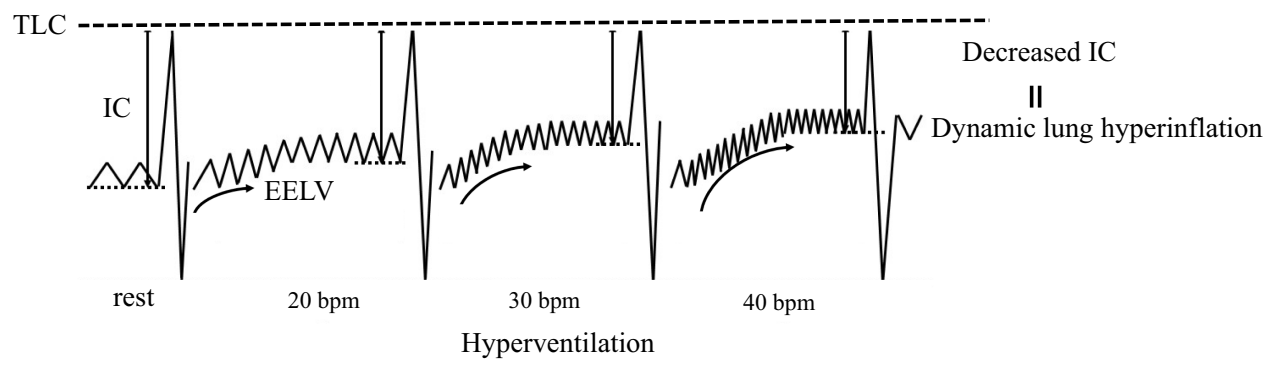

Figure I Metronome-paced incremental hyperventilation (MPIH) method in dynamic lung hyperinflation measurement. Abbreviations: TLC, total lung capacity; IC, inspiratory capacity; EELV, end-expiratory lung volume; bpm, breaths/min. 


\section{Evaluation of Dynamic Lung Hyperinflation by Constant Load Exercise Test}

After sufficient rest, symptom-limited CLE test was performed at a load of $60-70 \%$ of the maximum load in the incremental load exercise test. First, IC was measured in the subject at rest in the starting position of the exercise, and then the subject exercised for 3 minutes at a warm-up speed of $1 \mathrm{~km} / \mathrm{h}$ and a slope of $0 \%$ on the treadmill or $10 \mathrm{~W}$ on the ergometer. Following the warm-up phase, the exercise load was increased up to $60-70 \%$ of the maximum load in the incremental load exercise test and maintained. IC was measured every 2 minutes by maximum inspiratory maneuver during CLE. Modified Borg Scale (BS) regarding dyspnea and leg discomfort was also evaluated at the same time. The CLE test was performed to the point when the subject could no longer maintain exercise or 20 minutes had been reached followed by a 3-minute cool-down period with the same load as warm-up. ${ }^{15}$ IC was also measured during warm-up and cool-down phases. The IC at rest was expressed as $\mathrm{IC}_{\text {rest }}$. The most decreased IC ( $\left.\mathrm{IC}_{\text {lowest }}\right)$ was adopted among the measurements of IC during CLE, and the $-\mathrm{IC}_{\text {lowest }}\left(\mathrm{IC}_{\text {lowest }}-\mathrm{IC}_{\text {rest }}\right)$ was also evaluated. The exercise endurance time was adopted as exercise tolerance.

\section{Statistical Analysis}

The sample size was calculated as 35 to examine the correlation of DLH between exercise load and MPIH based on a previous study examining the accuracy of DLH measurement of exercise load and MPIH. ${ }^{18}$ According to this previous study, we calculated the sample size with power of $80 \%$, significance level of $5 \%$, and expected correlation coefficient of $r=0.46$. Wilcoxon's signed-rank test was used to compare CLE and MPIH. Furthermore, DLH was compared between the phenotypes of emphysema-dominant and emphysema-nondominant. Correlation analysis was performed using Spearman's rank correlation for single regression analysis. In all analyses, $p<0.05$ was taken to indicate statistical significance. SPSS ver. 25 was used for statistical analyses (SPSS Inc., Chicago, IL).

\section{Ethical Considerations}

All subjects were given an adequate explanation of the study and provided written informed consent to participation. This study was conducted in accordance with the ethical principles for medical research involving human subjects of the Declaration of Helsinki after obtaining approval from the Shinshu University of Medical Ethics Committee (approval number: 3705).

\section{Results}

\section{Physical Findings, Smoking History, Lung Function, and Medication History of Subjects}

Table 1 shows the basic physical findings, smoking history, spirometry, lung volume, and medication history of the subjects. A total of 35 subjects with mild-to-severe airflow limitation were enrolled in this study. Seventeen of 35 patients were classified as having emphysemadominant COPD, with the remaining 18 patients judged as having emphysema-nondominant COPD. Most of the subjects $(n=33)$ were on treatment with bronchodilators. No patient was receiving long-term oxygen therapy.

\section{Characteristics of Subjects in Incremental and Constant Load Exercise Tests}

Table 2 shows the results of incremental and constant load exercise tests. Eleven of the 35 subjects performed the CLE test with a treadmill and the remaining subjects performed the test using an ergometer. The peak $\dot{\mathrm{VO}}_{2}$, maximum $\dot{\mathrm{V}}_{\mathrm{E}}$, and maximum $\mathrm{RR}$ at CLE were about $87 \%, 84.5 \%$, and $95.6 \%$ of the incremental exercise load test, and most reached the same levels to the incremental exercise load test. The mean maximum RR at CLE was $30.1 \pm 0.8 \mathrm{bpm}$. All subjects showed mild desaturation $>$ $88 \%$ of $\mathrm{SpO}_{2}$ both at pre-exercise and during the incremental exercise test and CLE.

\section{Comparison of DLH Evaluated by MPIH and CLE}

Table 3 shows the results of DLH measured by the MPIH and CLE methods. The $\mathrm{IC}_{\text {rest }}$ measured by the MPIH method was significantly higher than that measured by the CLE method. However, the $\mathrm{IC}_{\text {lowest }}$ was not significantly different between the two methods, and the $-\mathrm{IC}_{\text {lowest }}$ was significantly lower in the MPIH method than the CLE method. The $\mathrm{IC}_{\text {lowest }}$ for $\mathrm{CLE}$ and the $-\mathrm{IC}_{\text {lowest }}$ for $\mathrm{MPIH}$ were significantly lower in emphysema-dominant COPD patients than in emphysema-nondominant COPD patients $\left(\mathrm{IC}_{\text {lowest }}: 1.70 \pm 0.11 \mathrm{~L}\right.$ vs $2.00 \pm 0.10 \mathrm{~L}, p=0.02$; and $-\mathrm{IC}_{\text {lowest }}:-0.54 \pm 0.08 \mathrm{~L}$ vs $\left.-0.28 \pm 0.08 \mathrm{~L}, p=0.045\right)$.

As shown in Figure 2, a significant positive correlation was observed between $\mathrm{IC}_{\text {lowest }}$ determined in the MPIH and 
Table I Subject Characteristics of Basic Physical Findings, Smoking History, Medication History, and Lung Function

\begin{tabular}{|c|c|}
\hline $\mathrm{n}$ & 35 \\
\hline Age, years & $75.9 \pm 1.4$ \\
\hline Sex (male/female) & $34 / 1$ \\
\hline Smoking history, packs $\times$ year & $53.2 \pm 5.2$ \\
\hline Past or current smoker, $\mathrm{n}$ & 31 \\
\hline Current smoker, $\mathrm{n}$ & 4 \\
\hline BMI, $\mathrm{kg} / \mathrm{m}^{2}$ & $23.0 \pm 0.5$ \\
\hline$\% \vee C, \%$ & $101.0 \pm 3.3$ \\
\hline IC, L & $2.32 \pm 0.08$ \\
\hline $\mathrm{FEV}_{\mathrm{l}}, \mathrm{L}$ & $1.79 \pm 0.09$ \\
\hline $\mathrm{FEV}_{1}, \%$ & $68.4 \pm 3.1$ \\
\hline $\mathrm{FEV}_{\mathrm{I}} / \mathrm{FVC}, \%$ & $57.3 \pm 1.6$ \\
\hline$\% F R C, \%$ & $96.9 \pm 3.0$ \\
\hline$\% R V, \%$ & $139.5 \pm 6.1$ \\
\hline$\% T L C, \%$ & $119.7 \pm 2.6$ \\
\hline RV/TLC, \% & $41.7 \pm 1.2$ \\
\hline$\% D L C O, \%$ & $69.9 \pm 3.0$ \\
\hline GOLD stage $(I, 2,3,4)$ & $7 / 21 / 6 / 1$ \\
\hline \multicolumn{2}{|l|}{ Phenotype of emphysema } \\
\hline Emphysema-dominant & 17 \\
\hline Emphysema-nondominant & 18 \\
\hline \multicolumn{2}{|l|}{ Treatment with inhaled agents } \\
\hline No drug, $n$ & 2 \\
\hline LAMA, $n$ & 4 \\
\hline LABA, $n$ & 0 \\
\hline LAMA+LABA, $n$ & 2 \\
\hline$L A B A+I C S, n$ & 23 \\
\hline LAMA \pm LABA $\pm I C S, n$ & 4 \\
\hline
\end{tabular}

Note: Values represent the mean \pm standard error of the mean. Abbreviations: BMI, body mass index; VC, vital capacity; IC, inspiratory capacity; FEV , forced expiratory volume in I second; FVC, forced vital capacity; FRC, functional residual capacity; RV, residual volume; TLC, total lung capacity; DLCO, lung-diffusion capacity for carbon monoxide; LAMA, long-acting muscarinic antagonist; LABA, long-acting beta 2 agonist; ICS, inhaled corticosteroid.

CLE methods $(\mathrm{r}=0.67, p<0.01)$. A significant positive correlation of $-\mathrm{IC}_{\text {lowest }}$ was also observed between the two methods $(\mathrm{r}=0.44, p<0.01)$.

\section{Correlation Between Dynamic Lung Hyperinflation and Exercise Endurance Time and Dyspnea BS Scale}

There was a significant positive correlation between the $\mathrm{IC}_{\text {lowest }}$ observed in MPIH and endurance time $(\mathrm{r}=0.62$, $p<0.001$ ), although no such significant correlation was observed between the $\mathrm{IC}_{\text {lowest }}$ during CLE and endurance time (Figure $3 \mathrm{~A}$ and B). Furthermore, the $\mathrm{IC}_{\text {lowest }}$ of MPIH was more significantly correlated with endurance time for emphysema-dominant COPD $(r=0.63, p=0.003)$ than for
Table 2 Subject Characteristics of Incremental- and ConstantLoad Exercise Test

\begin{tabular}{|c|c|c|}
\hline & $\begin{array}{l}\text { Incremental-Load } \\
\text { Test }\end{array}$ & $\begin{array}{l}\text { Constant-load } \\
\text { test }\end{array}$ \\
\hline $\mathrm{n}$ & 35 & \\
\hline Treadmill/ergometer & $11 / 24$ & \\
\hline$\dot{\mathrm{V}} \mathrm{O}_{2 \text { peak }}, \mathrm{mL} / \mathrm{kg} / \mathrm{min}$ & $15.8 \pm 1.0$ & $13.8 \pm 0.8$ \\
\hline$\dot{\mathrm{V}} \mathrm{CO}_{2}$ peak, $\mathrm{mL} / \mathrm{kg} / \mathrm{min}$ & $16.9 \pm 1.2$ & $13.6 \pm 0.8$ \\
\hline$\dot{\mathrm{V}} \mathrm{E}_{\text {peak, }} \mathrm{L} / \mathrm{min}$ & $45.3 \pm 2.4$ & $38.3 \pm 2.0$ \\
\hline $\mathrm{RR}_{\text {peak }}$, breaths/min & $31.5 \pm 0.8$ & $30.1 \pm 0.9$ \\
\hline$P R$ pre, beats/min & $83.9 \pm 2.4$ & $87.4 \pm 2.0$ \\
\hline$P R_{\text {max }}$, beats/min & $139.0 \pm 5.7$ & $121.4 \pm 7.3$ \\
\hline $\mathrm{SpO}_{2}$ pre, $\%$ & $93.9 \pm 1.2$ & $94.9 \pm 0.4$ \\
\hline $\mathrm{SpO}_{2}$ lowest, $\%$ & $92.1 \pm 0.6$ & $91.2 \pm 0.7$ \\
\hline $\begin{array}{l}\text { Exercise endurance } \\
\text { time, } s\end{array}$ & & $362.9 \pm 49.5$ \\
\hline Dyspnea BS $\max$ & & $5.3 \pm 0.4$ \\
\hline Leg discomfort BS ${ }_{\max }$ & $6.0 \pm 0.5$ & \\
\hline
\end{tabular}

Notes: Values represent the mean \pm standard error of the mean. The "Peak" value was the average value for 10 seconds before the end of exercise.

Abbreviations: $\mathrm{V}_{2}$ peak, oxygen uptake at peak exercise; $\dot{\mathrm{V}} \mathrm{CO}_{2}$ peak, carbon dioxide output at peak exercise; $\mathrm{VE}_{\text {peak, }}$, minute ventilation at peak exercise; $\mathrm{RR}_{\text {peak, }}$ respiratory rate at peak exercise; $P R_{\text {pre, }}$ minimum pulse rate at rest; $P R{ }_{\text {max }}$, maximum pulse rate during exercise; $\mathrm{SpO}_{2}$ pre, percutaneous oxygen saturation at rest; $\mathrm{SpO}_{2}$ lowest lowest percutaneous oxygen saturation during exercise; $\mathrm{BS}_{\max }$, maximum modified Borg scale.

emphysema-nondominant COPD $(\mathrm{r}=0.42, p=0.08)$. Weak but significant correlations between $-\mathrm{IC}_{\text {lowest }}$ and maximum modified Borg scale were observed for each method (MPIH: $\mathrm{r}=0.38, p=0.02$; and CLE: $\mathrm{r}=0.37, p=0.03$ ), with no significant differences between the phenotypes.

\section{Discussion}

In the present study, $\mathrm{IC}_{\text {lowest }}$ and $-\mathrm{IC}_{\text {lowest }}$ showed significant correlations between the two methods. The endurance time was significantly correlated with the $\mathrm{IC}_{\text {lowest }}$ following MPIH, but not with that observed in the CLE test. However, the maximum dyspnea Borg scale was significantly correlated with $-\mathrm{IC}_{\text {lowest }}$ in both methods. When the subjects were divided by phenotype according to the dominancy of emphysema, $\mathrm{IC}_{\text {lowest }}$ in CLE and $-\mathrm{IC}_{\text {lowest }}$ in MPIH were significantly lower for emphysema-dominant $\mathrm{COPD}$, and the $\mathrm{IC}_{\text {lowest }}$ of MPIH was more significantly correlated with endurance time for emphysema-dominant COPD. These findings suggested that the DLH measured by our convenient MPIH method is closely correlated with that measured by the conventional exercise load test, and was a more useful predictor of exercise tolerance, especially in emphysema-dominant COPD. Our convenient MPIH method may provide a clinically useful screening 
Table 3 Comparison of Dynamic Lung Hyperinflation Measured by Exercise Load and Hyperventilation

\begin{tabular}{|c|c|c|c|}
\hline & Total & Emphysema & Nonemphysema \\
\hline $\mathrm{n}$ & 35 & 17 & 18 \\
\hline \multicolumn{4}{|l|}{ IC measured by } \\
\hline \multicolumn{4}{|l|}{ CLE } \\
\hline \multirow[t]{2}{*}{$I C_{\text {rest }}, \mathrm{L}$} & $2.07 \pm$ & $2.02 \pm 0.09$ & $2.12 \pm 0.11$ \\
\hline & 0.07 & & \\
\hline \multirow{2}{*}{$I C_{\text {warm-up, }} \mathrm{L}$} & $2.07 \pm$ & $1.97 \pm 0.11$ & $2.17 \pm 0.13$ \\
\hline & 0.09 & & \\
\hline \multirow[t]{2}{*}{$I C_{\text {cool-down }}, \mathrm{L}$} & $1.91 \pm$ & $1.81 \pm 0.13$ & $2.01 \pm 0.11$ \\
\hline & 0.09 & & \\
\hline \multirow[t]{2}{*}{$I C_{\text {lowest }} \mathrm{L}$} & $1.86 \pm$ & $1.70 \pm 0.1 \mathrm{I}^{\dagger}$ & $2.00 \pm 0.10$ \\
\hline & 0.08 & & \\
\hline \multirow[t]{2}{*}{$-I C_{\text {lowest }} \mathrm{L}$} & $-0.21 \pm$ & $-0.32 \pm 0.10$ & $-0.11 \pm 0.05$ \\
\hline & 0.06 & & \\
\hline \multicolumn{4}{|l|}{ IC measured by } \\
\hline \multicolumn{4}{|l|}{ MPIH } \\
\hline \multirow[t]{2}{*}{$I_{\text {rest }}, \mathrm{L}$} & $2.31 \pm$ & $2.25 \pm 0.11$ & $2.36 \pm 0.10$ \\
\hline & $0.08 * *$ & & \\
\hline \multirow[t]{2}{*}{$\mathrm{IC}_{20}, \mathrm{~L}$} & $2.22 \pm$ & $2.06 \pm 0.13$ & $2.36 \pm 0.12$ \\
\hline & 0.09 & & \\
\hline \multirow[t]{2}{*}{$\mathrm{IC}_{30}, \mathrm{~L}$} & $2.05 \pm$ & $1.85 \pm 0.12$ & $2.23 \pm 0.12$ \\
\hline & 0.09 & & \\
\hline \multirow[t]{2}{*}{$\mathrm{IC}_{40}, \mathrm{~L}$} & $1.92 \pm$ & $1.73 \pm 0.12$ & $2.10 \pm 0.12$ \\
\hline & 0.09 & & \\
\hline \multirow[t]{2}{*}{$I C_{\text {lowest }}, L$} & $1.90 \pm$ & $1.72 \pm 0.11$ & $2.08 \pm 0.12$ \\
\hline & 0.09 & & \\
\hline \multirow[t]{2}{*}{$-I C_{\text {lowest }}, \mathrm{L}$} & $-0.42 \pm$ & $-0.54 \pm 0.08^{\dagger}$ & $-0.28 \pm 0.08$ \\
\hline & $0.06 * *$ & & \\
\hline
\end{tabular}

Notes: Values represent the mean \pm standard error of the mean; $* * p<0.01$ vs same IC index measured by constant load exercise (CLE) among total subjects. ${ }^{\dagger} p<0.05$ vs nonemphysema (emphysema-nondominant phenotype COPD).

Abbreviations: CLE, constant load exercise; IC, inspiratory capacity; MPIH, metronome-paced incremental hyperventilation; RR, respiratory rate; bpm, breaths/min; IC $C_{\text {rest }}$ IC at rest; IC $C_{\text {warm-up, }}$ mean IC at warm-up; IC $C_{\text {cool-down, mean }}$ IC at cool-dawn; IC lowest lowest IC; $-I C_{\text {lowest }}$, decrease in IC from IC $C_{\text {rest }}$ to IC $C_{\text {lowest; }}$; $I C_{20}$, IC at RR of $20 \mathrm{bpm} ; I_{30}$, IC at RR of $30 \mathrm{bpm} ; \mathrm{IC} 40$, IC at RR of $40 \mathrm{bpm}$.

surrogate to predict not only the degree of DLH during exercise but also exercise tolerance and dyspnea.

\section{Comparison of DLH Measured by the MPIH and CLE Methods}

Gelb et al compared IC reduction during both metronomepaced hyperventilation at twice the resting respiratory rate for $20 \mathrm{~s}$ and symptom-limited incremental cycle ergometry when the final respiratory rate was also twice the resting rate before and after ipratropium bromide treatment in patients with moderate-to-severe COPD. ${ }^{19}$ They reported a significant correlation of the decreases in IC between metronome-paced hyperventilation and incremental cycle ergometry in IC after ipratropium treatment. However, there was no correlation before treatment and the sample size was small. In the present study with an optimized sample size, both $\mathrm{IC}_{\text {lowest }}$ and $-\mathrm{IC}_{\text {lowest }}$ showed significant correlations between the two methods.

The decreases in IC during exercise have been reported to be dependent on increased respiratory rate in COPD. ${ }^{3}$ The maximum respiratory rate of MPIH was $40 \mathrm{bpm}$, whereas the mean respiratory rate at the peak during exercise was $30.1 \pm$ $0.9 \mathrm{bpm}$ in CLE. Therefore, the $\mathrm{IC}_{\text {lowest }}$ was expected to be lower in MPIH than in CLE. However, the $\mathrm{IC}_{\text {lowest }}$ was similar in the two methods although the $-\mathrm{IC}_{\text {lowest }}$ was greater in MPIH than in CLE, possibly due to the larger IC values at rest in MPIH than in CLE. It might be considered that the ICs were affected by the position and fixation of the arm in CLE. It has been reported that elevation of the upper limbs and forward flexing posture reduce VC and IC. ${ }^{20}$ The arms were positioned in a forward flexing posture in the ergometer and treadmill. Therefore, the ICs in CLE may have been affected, resulting in lower values compared with those in MPIH. Another reason is that the subjects did not perform enough inspiratory maneuvers in CLE. The mean age of the subjects in the present study was 75.9 years old. Most subjects who enroll in clinical COPD research in Japan are over 70 years old and are more elderly compared with subjects in clinical research performed outside Japan. ${ }^{21}$ It was doubtful whether the elderly subjects could

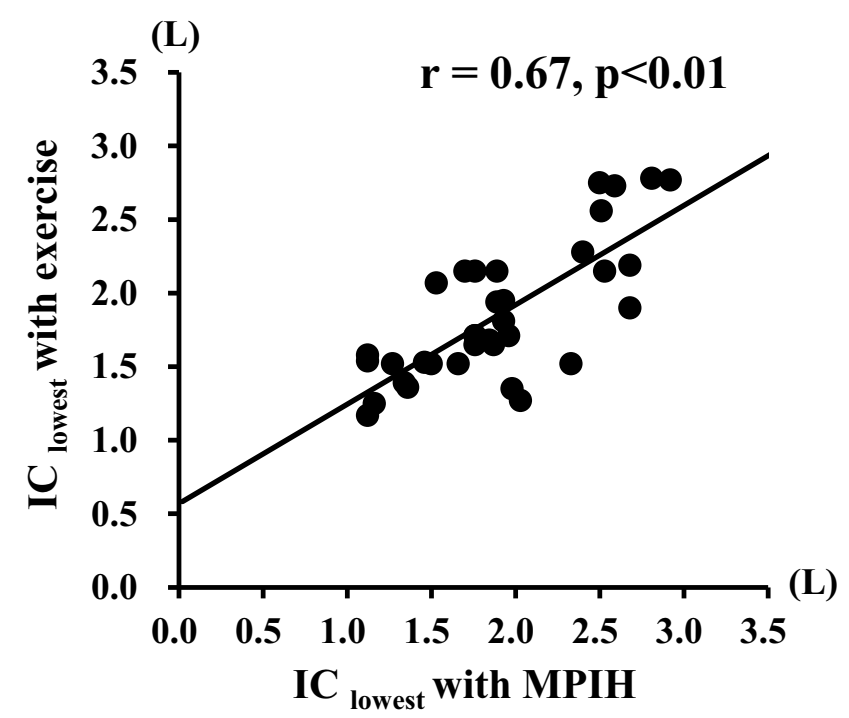

Figure 2 Correlation of dynamic lung hyperinflation measured by exercise load and metronome-paced incremental hyperventilation (MPIH).

Note: Lowest IC as the deceased IC was significantly correlated between the two methods $(r=0.67, p<0.01)$.

Abbreviations: IC, inspiratory capacity; MPIH, metronome-paced incremental hyperventilation; IC lowest, lowest IC among the ICs measured by each method. 


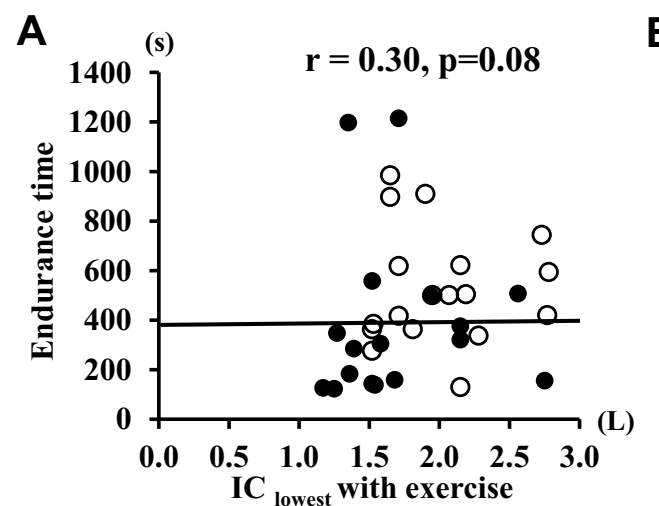

O Emphysema - nondominant

- Emphysema - dominant
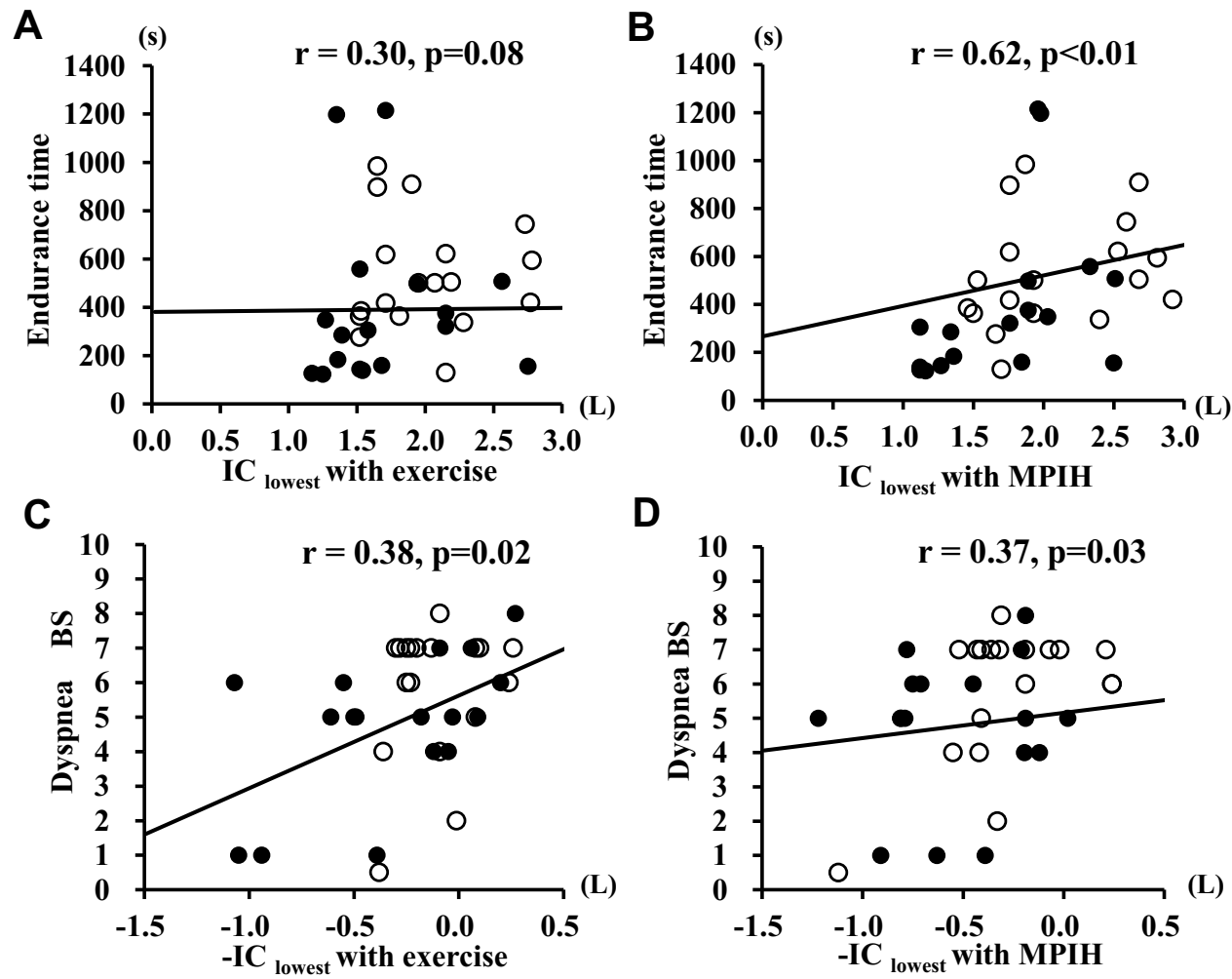

D

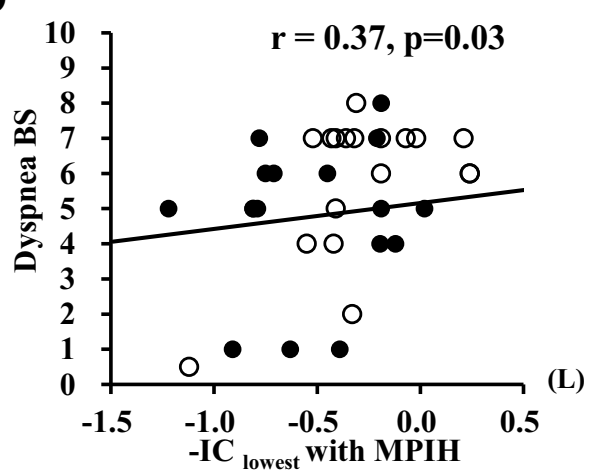

Figure 3 Correlation between dynamic lung hyperinflation and exercise tolerance or dyspnea on exertion.

Notes: Closed circles are emphysema-dominant COPD and open circles are emphysema-nondominant COPD. Lowest IC as the decreased IC with exercise was not significantly correlated with exercise endurance time. (A). Lowest IC with MPIH was significantly correlated with exercise endurance time (B). The decreases in IC with exercise and MPIH were significantly correlated with modified Borg Scale of dyspnea (C and D).

Abbreviations: IC, inspiratory capacity; MPIH, metronome-paced incremental hyperventilation; IC lowest, lowest IC among the ICs measured by each method; -IC lowest, decreases in IC from at rest to $\mathrm{IC}_{\text {lowest }}$.

perform maximum inspiratory maneuver not only during exercise but also at rest while wearing a facemask or not. As a result, the decreased IC in CLE may have been lower than in MPIH in the present study. Therefore, we believe that MPIH can more accurately evaluate DLH depending on respiratory rate versus the CLE method and the MPIH method is easy to perform for both elderly subjects and severely ill patients.

\section{Correlation of Exercise Tolerance and Dynamic Lung Hyperinflation}

The exercise endurance time was significantly correlated with the $\mathrm{IC}_{\text {lowest }}$ following MPIH. We previously demonstrated that the decreased IC and the decreases in IC following MPIH were significantly correlated with exercise tolerance evaluated by 6-minute walking distance in COPD as same as in this study. ${ }^{8}$ However, a significant correlation between endurance time and the $\mathrm{IC}_{\text {lowest }}$ or $-\mathrm{IC}_{\text {lowest }}$ in CLE could not be obtained in the present study. This may have been due to exercise limiting factors other than DLH on exercise endurance time. Exercise tolerance is determined by various factors including $\mathrm{DLH},{ }^{1}$ especially in COPD patients with hyperinflation and the emphysema-dominant phenotype. ${ }^{13,22}$ The present study showed greater DLH in both methods and a more significant correlation between the DLH of MPIH and endurance time in emphysemadominant COPD. However, the MPIH method can only evaluate DLH depending on an increase in respiratory rate. The limiting factor of exercise tolerance is not only DLH but also other factors such as airflow limitation, hypoxemia, and leg discomfort, all of which are evaluated by CLE. Leg discomfort has been reported to be a major factor in exercise limitation (54.1\%) on cardiopulmonary exercise test, and these subjects had significantly higher predicted $\mathrm{FEV}_{1} \cdot{ }^{23}$ In the present study, the mean BS of leg discomfort was higher than dyspnea BS, which may have been due to more advanced age and mild severity. For these reasons, a significant correlation between DLH and exercise tolerance was not consistently obtained in CLE. Even in this 
population, a significant correlation was observed between $\mathrm{IC}_{\text {lowest }}$ following MPIH and exercise tolerance.

There were significant correlations between the decreases in IC and dyspnea for both methods, although the correlation coefficients were weak. Various factors may contribute to dyspnea during exercise as well as exercise tolerance. The patients with emphysema-nondominant COPD showed severe dyspnea despite their DLH being mild. In these subjects, airflow limitation, but not DLH, may have contributed to the dyspnea. ${ }^{22}$ As the emphysema-nondominant COPD patients with exercise intolerance associated with airflow limitation rather than DLH were mixed in the present study, the correlation between dyspnea and DLH may have been weaker in each method. In emphysema-dominant COPD, dyspnea is more associated with DLH, and a large DLH is shown in MPIH; thus, ${ }^{13,22}$ it is more clinically important to be evaluated for DLH by the MPIH method, particularly for emphysema-dominant COPD patients.

\section{Limitations}

The present study had several limitations. First, the subjects were elderly. Most subjects who enroll in COPD research in Japan are over 70 years old. ${ }^{21}$ Moreover, the majority of subjects could not maintain exercise for more than 10 minutes at $80 \%$ exercise load of CLE. Therefore, the constant exercise load was set lower (from $60 \%$ to $70 \%$ ) than in previous studies. ${ }^{15,17}$ Second, the incremental load exercise test and CLE test were not performed in a uniform way, and peak $\mathrm{VO}_{2}$ was significantly higher in subjects using the treadmill than in those who used the ergometer. However, the $\mathrm{IC}_{\text {lowest }}$ and $-\mathrm{IC}_{\text {lowest }}$ were comparable between the two tests. These limitations may have influenced the exercise limitation factors.

\section{Conclusion}

The DLH assessed by our developed MPIH method and the conventional method of exercise load was closely correlated, and exercise tolerance evaluated by endurance time during CLE was significantly correlated with the DLH following MPIH, but not with that during CLE. Therefore, MPIH may be a convenient method to predict exercise tolerance and dyspnea as a clinically useful synergic screening surrogate for DLH during exercise.

\section{Acknowledgments}

The authors wish to thank Koganei Co., Ltd. (Tokyo, Japan) for providing the measuring equipment and facilities for this study.
The authors also wish to thank Mahoko Sano (doctoral student, Shinshu University, Nagano, Japan) for help in data collection.

\section{Funding}

This research received no specific grant from any funding agency in the public, commercial, or not-for-profit sectors.

\section{Disclosure}

Keisaku Fujimoto reports collaborative research fees from Murata Manufacturing Co., Ltd., Denso Corporation, Seiko Epson Corporation, and KOGANEI Co., Ltd.; personal fees from Nippon Boehringer Ingelheim Co., Ltd., Meiji Seika Farma Co., Ltd., GlaxoSmithKline Co., Ltd., Teijin Farma Japan Co., Ltd., Teijin Home Healthcare Limited, Astellas Pharma Co., Ltd., AstraZeneca Japan Co., Ltd., Chest Co., Ltd., Phillips Japan Ltd., Fukuda Densi Co., Ltd., Fukuda Lifetec Co., Ltd., and Air Water Inc., outside the submitted work. The authors report no other conflicts of interest in this work.

\section{References}

1. O'Donnell DE, Revill SM, Web KA. Dynamic hyperinflation and exercise intolerance in chronic obstructive pulmonary disease. $\mathrm{Am}$ J Respir Crit Care Med. 2001;164:770-777.

2. O'Donnell DE, Laveneziana P. The clinical importance of dynamic lung hyperinflation in COPD. COPD. 2006;3:219-232. doi:10.1080/ 15412550600977478

3. O'Donnell DE, Webb KA. Exertional breathlessness in patients with chronic airflow limitation. Am Rev Respir Dis. 1993;148:1351-1357. doi:10.1164/ajrccm/148.5.1351

4. O'Donnell DE, Webb KA, Neder JA. Lung hyperinflation in COPD: applying physiology to clinical practice. COPD Res Pract. 2015;1:1-12. doi:10.1186/s40749-015-0008-8

5. Puente-Maestu L, Stringer WW. Hyperinflation and its management in COPD. Int J Chron Obstruct Pulmon Dis. 2006;1:381.

6. Fujimoto K, Yamazaki H, Ura M, Kitaguchi Y. Efficacy of tiotropium and indacaterol monotherapy and their combination on dynamic lung hyperventilation in COPD: a random open-label crossover study. Int J Chron Obstruct Pulmon Dis. 2017;12:3195-3201. doi:10.2147/COPD.S149054

7. Kawachi S, Fujimoto K. Efficacy of tiotropium and olodaterol combination therapy on dynamic lung hyperinflation evaluated by hyperventilation in COPD: an open-label, comparative before and after treatment study. Int J Chron Obstruct Pulmon Dis. 2019;14:1167-1176. doi:10.2147/COPD. S201106

8. Kawachi S, Fujimoto K. Usefulness of a newly developed spirometer to measure dynamic lung hyperinflation following incremental hyperventilation in patients with chronic obstructive pulmonary disease. Intern Med. 2019;58:39-469. doi:10.2169/internalmedicine.1212-18

9. Global Initiative for Chronic Obstructive Lung Disease, Global strategy for the diagnosis, management and prevention of chronic obstructive pulmonary disease (2019 report), World Health Organization; 2019 [cited 2019 February 26]. Available from: https://goldcopd.org/wp-content/uploads/2018/11/GOLD-2019-v1. 7-FINAL-14Nov2018-WMS.pdf. Accessed May 052020.

10. Sasaki E, Nakamura M, Kida K, et al. Reference values for spirogram and blood gas analysis in Japanese non-smoking healthy adults. $J$ Jpn Respir Soc. 2001;39:383-399. 
11. Nishida S, Kambe M, Sewake N, Takano M, Kawane H. Pulmonary function in healthy subjects and its prediction-5: pulmonary diffusing capacity in adults. Jpn J Clin Pathol. 1976;24:941-947.

12. Boren HG, Kory RC, Syner JC. The veterans administration army cooperative study of pulmonary function. Am J Med. 1966;41:96-114. doi:10.1016/0002-9343(66)90008-8

13. Fujimoto K, Kitaguchi Y, Kanda S, Urushihata K, Hanaoka M, Kubo K. Comparison of efficacy of long-acting bronchodilators in emphysema dominant and emphysema nondominant chronic obstructive pulmonary disease. Int $J$ Chron Obstruct Pulmon Dis. 2011;6:219. doi:10.2147/COPD.S18461

14. Goddard PR, Nicholson EM, Laszlo G, Watt I. Computed tomography in pulmonary emphysema. Clin Radiol. 1982;33:379-387. doi:10.1016/S0009-9260(82)80301-2

15. Berton DC, Reis M, Siqueira ACB, et al. Effects of tiotropium and formoterol on dynamic hyperinflation and exercise endurance in COPD. Respir Med. 2010;104:1288-1296. doi:10.1016/j.rmed.2010.05.017

16. Yamamoto M. Development of ramp protocol for use of treadmill and a formula for prediction of oxygen uptake. Jpn J Appl Physiol. 1993;23:1-13.

17. O’Donnell DE, Casaburi R, Frith P, et al. Effects of combined tiotropium/olodaterol on inspiratory capacity and exercise endurance in COPD. Eur Respir J. 2017;49:1601348. doi:10.1183/ 13993003.01348-2016
18. Lahaije AJ, Willems LM, van Hees HW, Dekhuijzen PR, van Helvoort HA, Heijdra YF. Diagnostic accuracy of metronome - paced tachypnea to detect dynamic hyperinflation. Clin Physiol Funct Imaging. 2013;33:62-69. doi:10.1111/j.1475-097X.2012.01164.X

19. Gelb AF, Gutierrez CA, Weisman IM, Newsom R, Taylor CF, Zamel N. Simplified detection of dynamic hyperinflation. Chest. 2004;126:1855-1860. doi:10.1378/chest.126.6.1855

20. Dolmage TE, Maestro L, Avendano MA, Goldstein RS. The ventilatory response to arm elevation of patients with chronic obstructive pulmonary disease. Chest. 1993;104:1097-1100. doi:10.1378/chest.104.4.1097

21. Ichinose M, Minakata Y, Motegi T, et al. Efficacy of tiotropium/olodaterol on lung volume, exercise capacity, and physical activity. Int J Chron Obstruct Pulmon Dis. 2018;13:1407. doi:10.2147/COPD.S166023

22. Diaz O, Villafranca C, Ghezzo H, et al. Role of inspiratory capacity on exercise tolerance in COPD patients with and without tidal expiratory flow limitation at rest. ERJ Open Res. 2000;16:269-275.

23. Mirdamadi M, Rahimi B, Safavi E, Abtahi H, Peiman S. Correlation of cardiopulmonary exercise testing parameters with quality of life in stable COPD patients. J Thorac Dis. 2016;8:2138. doi:10.21037/ jtd.2016.07.07

\section{Publish your work in this journal}

The International Journal of COPD is an international, peer-reviewed journal of therapeutics and pharmacology focusing on concise rapid reporting of clinical studies and reviews in COPD. Special focus is given to the pathophysiological processes underlying the disease, intervention programs, patient focused education, and self management protocols. This journal is indexed on PubMed Central, MedLine and CAS. The manuscript management system is completely online and includes a very quick and fair peer-review system, which is all easy to use. Visit http://www.dovepress.com/testimonials.php to read real quotes from published authors. 